\title{
Electrostatic separation of mineral and vegetal powders with a custom built corona separator: application to biorefinery of rice husk
}

\author{
Rova Karine Rajaonarivony ${ }^{1}$, Xavier Rouau ${ }^{1}$, Lucien Dascalescu ${ }^{2}$, Claire Mayer-Laigle ${ }^{1 *}$ \\ ${ }^{1}$ IATE UMR 1208 INRA-CIRAD-SupAgro-UM, 2 place Pierre Viala - 34060 Montpellier, France \\ ${ }^{2}$ Institut PPRIME, UPR 3346, 4 Av. de Varsovie, 16021 Angoulême, France
}

\begin{abstract}
In a dry biorefinery scheme, the separation of plant materials into powders rich in the constituents of interest is a crucial step. In recent years, electrostatic separation of agri-resources has sparked a growing interest for its potentialities, but optimization efforts remain to be done especially in case of fine powders. In this study a custom-designed corona-electrostatic separator has been built and its usage for the separation of mineral (ash from rice husk) and vegetal powders (cellulose fibers) with different particle size distributions has been studied. First, the powders have been characterized by their electric charge decay curves and their behaviour on the separator was studied. At a second time, separation tests have been carried out with blends of these two powders, and with native, finely ground, rice husk powder (constituted of both mineral and vegetal particles). In each case, the efficiency of the process was evaluated.
\end{abstract}

\section{Introduction}

Plant materials, structurally organized in a multilayer composite containing different tissues [1] are excellent sources of raw materials for many applications as biofuels, green chemicals (surfactant, resin...) or biomaterials (fiber). In a plant bio-refinery scheme, the first step consists in the separation of agri-resources materials into their major constituents (carbohydrates, proteins, lignin, lipids, polyphenols, minerals...). Dry fractionation processes, could be seen as an interesting alternative to expensive hydo-chemical processes which induce a degradation of the native functionalities of the constituents and are known to have a detrimental environmental impact. These processes usually combine different unit operations of pre-treatment, grinding and physical separation to gradually de-structure and fractionate the plant materials at tissue $(100 \mu \mathrm{m})$ or subcellular scale $(10 \mu \mathrm{m})$ [2].

Among all the separation processes, the electrostatic separation emerged as an eco-friendly technology since it allows the preparation of fractions enriched in the constituents of interest from biomass particles ranging between 10 and $500 \mu \mathrm{m}$. In an electrostatic separator, particles are first charged by triboelectric charging, by conductive induction or by ion bombardment and then sorted in a high intensity electric field. Existing electrostatic separators are not directly transposable to agri-resources processing since the particles obtained in a dry bio-refinery scheme are smaller and/or lighter than those encountered in polymer recycling or mineral beneficiation industries. In the scientific literature, two devices, based on two different principles, are mainly used for the electrostatic separation of plant materials.
The first one, inspired by the industrial free fall electrostatic separator demonstrated its potentiality for processing many plant raw materials [3-5], but presents a weak flexibility. The second (belt-type coronaelectrostatic separator), akin to a corona drum separator, have been used for removing fibers [6-7], in relatively coarse biomass powder (median size, d50>1 mm). The present study is aimed at the separation of mineral (silica) and vegetal parts of a raw plant material: rice husk, using a custom-designed corona-electrostatic separator.

Rice husk is an agricultural by-product composed of roughly $85 \%$ lignocellulosic material and $15 \%$ amorphous silica. The high mineral content in the rice husk limited its utilization mainly to the energy production by combustion, with incorporation of the ash in the production of Portland cement or steel. In addition, amorphous silica is used in several other applications, such as ore metal smelting, water purification, rubber and glue additives, etc. but it is currently produced by wet or thermic processes, which are high energy consumers. The separation of the amorphous silica of rice husk by dry processes would allow to expand the field of potential usage and create added value for this by-product.

To dissociate the effects related to the powder properties and those of device parameters, a preliminary study was conducted on model powders simulating the vegetal part (cellulose fiber) and the mineral part (ash form burnt rice husk) of rice husk, with different particle size distributions. Powders have been characterized by their charge decay curves. Their behaviours on the separator were studied and separation tests were carried out with blends of mineral and vegetal powders. The different 
assays were compared using a separation index to define the best process parameters, which were then applied to the separation of ground rice husk.

\section{Materials and Methods}

In the device, a vibrating hopper is used to deposit the powder on the conveyor as isolate particles in order to limit the interparticle interactions during the separation process. In contact with the grounded conveyor, the conducting particles quickly loose the charge acquired by corona discharge ; when they enter in the electric field generated by the rotating roll electrode they get charged by electrostatic induction, detach from the conveyor, and may be recovered in bin B. Many of them change again the sign of their charge after the impact with the rotating roll electrode, and will be collected neither in bin $\mathrm{B}$, nor in bin $\mathrm{A}$. The poor- and nonconducting particles that loose their charge more slowly can be attracted to the rotating roll electrode by the electric Coulomb force. The corona discharge and the roll electrode in the custom built separator are powered by a high voltage generator between $-60 \mathrm{kV}$ and $+60 \mathrm{kV}$. The velocity of the conveyor belt and the roll electrode, the distance between the conveyor and the roll electrode $\left(d_{e}\right)$ are adjustable. Thus the charge of the particles, the contact time between the particles and the conveyor, and the intensity of the electrical field could be managed.

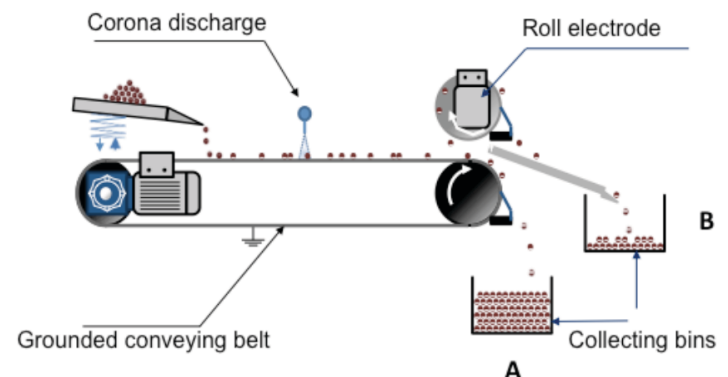

Fig 1: Custom built corona belt separator

From a theoretical point of view and in a first approximation, it can be assumed that a particle of mass $m$ and carrying a charge $q_{a}$ can be attracted by the roll electrode connected at a high voltage $V$, if the electric attraction force $F_{e}$ surpasses the weight $P$, that is:

$$
\begin{gathered}
F_{e}=q_{e} * E>P=m * g \\
E=\frac{V}{d_{e}}
\end{gathered}
$$

where $g$ is the gravitational acceleration and $E$ is the electric field strength. By increasing the ratio $q_{a} / m$ the ability of a powder to be attracted by the roll electrode is enhanced. As a consequence, the efficiency of the separation is related to charge of the particle, its mass, its shape and its composition.

Powders of ash from rice husk, cellulose fibers and ground rice husk were studied in this work. The ash rice husk were recovered at the output of an industrial furnace at $900{ }^{\circ} \mathrm{C}$. The ash was sieved with a screen of $0.5 \mathrm{~mm}$ to eliminate coarser particles. The powder obtained was called ARH cl2. A part of this fraction was ground with a ball mill to obtain a finer powder $\left(\mathrm{d}_{50}=30\right.$ $\mu \mathrm{m})$ called ARH cll. The cellulose fibers ARBOCEL came from the company JRS France. Two types of fibers were selected: $\mathrm{Cel} \mathrm{cl} 2$ and $\mathrm{Cel}$ cllfor their differences in fiber length. To obtain a finer powder of rice husk $(\mathrm{RH}$ cl1), the native rice husk was ground with a ball mill during 5 hours until it reached a $\mathrm{d}_{50}=30 \mu \mathrm{m}$. The main size characteristics of the different powders are summarized in table 1. Size dimensions of cellulose fibers are data from supplier and the size characteristics of rice husk and ash powder were determined by laser diffraction using a laser granulometer (Malvern, France).

\begin{tabular}{|c|c|}
\hline $\begin{array}{l}\text { Powder name and } \\
\text { description }\end{array}$ & $\begin{array}{c}\text { Main size characteristics } \\
(\mathrm{d} 10, \mathrm{~d} 50, \mathrm{~d} 90)\end{array}$ \\
\hline $\begin{array}{l}\text { ARH cll : Ash from rice } \\
\text { husk sieved and ground }\end{array}$ & $7 \mu \mathrm{m}, 30 \mu \mathrm{m}, 72 \mu \mathrm{m}$ \\
\hline $\begin{array}{c}\text { ARH cl2 : Ash from rice } \\
\text { husk sieved }\end{array}$ & $81 \mu \mathrm{m}, 232 \mu \mathrm{m}, 565 \mu \mathrm{m}$ \\
\hline $\begin{array}{c}\text { RH cl1 : Ground rice } \\
\text { husk }\end{array}$ & $3 \mu \mathrm{m}, 33 \mu \mathrm{m}, 126 \mu \mathrm{m}$ \\
\hline Cel cl1 : Cellulose fiber & $\begin{array}{l}\text { Fiber diameter }=20 \mu \mathrm{m} \\
\text { Fiber length }: 60 \mu \mathrm{m}\end{array}$ \\
\hline Cel cl 2 : Cellulose fiber & $\begin{array}{l}\text { Fiber diameter }=20 \mu \mathrm{m} \\
\text { Fiber length }: 300 \mu \mathrm{m}\end{array}$ \\
\hline
\end{tabular}

Table 1: Main powder size characteristics

All the tests described above were carried out at a relative humidity between 30 and $40 \%$. In these conditions the dielectric breakdown field of the atmospheric air is roughly $30 \mathrm{kV} \cdot \mathrm{cm}^{-1}$.

\section{Result and discussion}

\subsection{Charge decay curves}

The electrical properties (conductivity, permittivity) are not known for these materials in powder form. To estimate their electrical behaviours, charge decay curves were recorded for each class of materials after a positive $(+15 \mathrm{kV})$ or a negative $(-15 \mathrm{kV})$ corona discharge. The distance between the corona electrode and the conveyor was set to $4 \mathrm{~cm}$, the velocity of the conveyor to 2,6 $\mathrm{m} / \mathrm{min}$ and the position of the corona electrode was modified in order to adjust the contact time between the particles and the ground conveyor (residence time between 4 and $30 \mathrm{~s}$ ). The charge of the particle was measured in a Faraday cage at the conveyor outlet, in two replicate experiments with $2 \mathrm{~g}$ of powders. The charge is expressed as $\mathrm{mC} / \mathrm{g}$ since the attraction of the powder by the roll electrode is a function $q_{a} / m$ (figure 2). The dotted lines in red and blue represent the residual charge of the finest and the coarsest powders, respectively. The residual charge is measured when no corona discharge is applied to the powder. It corresponds to the value towards the charge tends when the powder is 
in contact to the ground during an infinite time. For all powders, the charges do not evolve significantly with the range of time used. Thus, the residence time of the powder on the ground conveyor will not be a significant parameter in the optimization of the separation. The value of the charge of ground rice husk is almost twice the one of ash from rice husk and cellulose reflecting the fact that $\mathrm{ARH}$ and $\mathrm{Cel}$ are more conductive powders. Interestingly, it is well noticed that the value of the charge of the powder is less important and exhibits a higher error bar related to a weak repeatability of the different assays with a negative corona discharge. In addition, when a negative corona discharge is applied to the ARH, the measured charge of the powder is positive. These phenomena could be partially explained by an induction effect on highly conductive powders as described by Tilmatine and al [8].

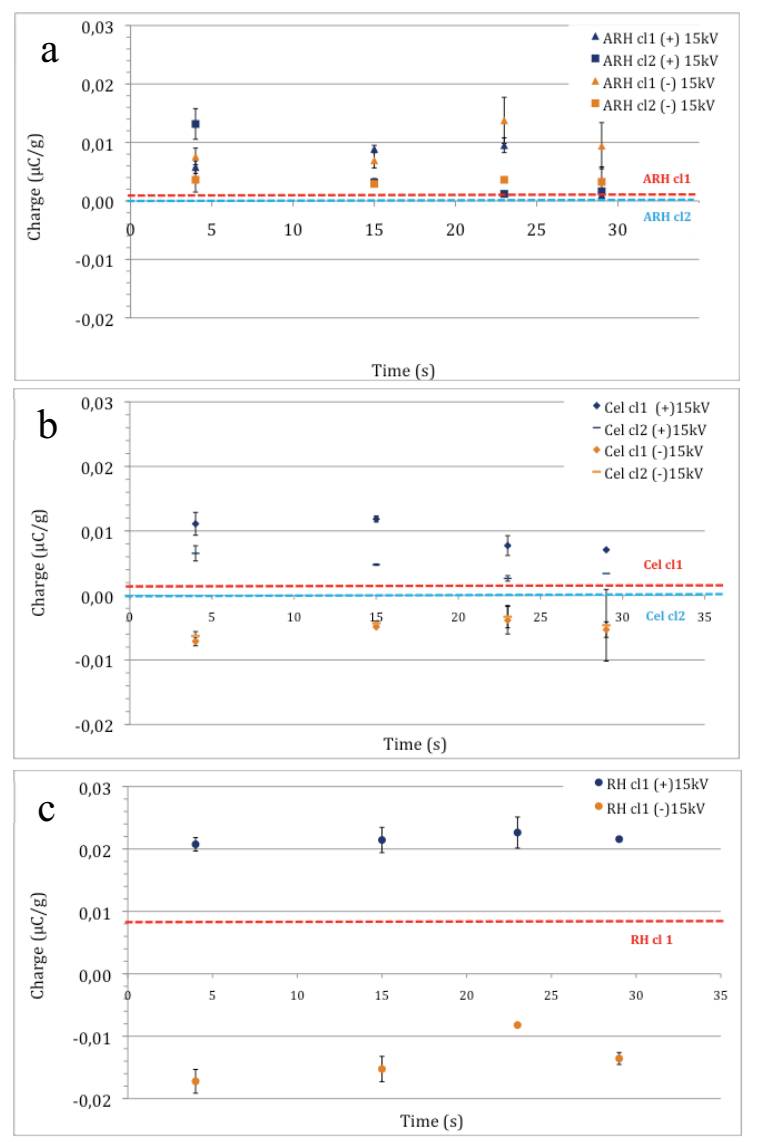

Fig. 2: Charge decay of ash from rice husk (a), cellulose (b) and ground rice husk (c), in contact with the grounded metallic conveyor belt

\subsection{Behaviour of powders on the separator}

The different model powders were tested on the separator in two different configurations (table 2). In configuration 1, the corona discharge was not activated and only the induction effects generated by the roll electrode was responsible for the charge and the attraction of the particle. In the configuration 2 , the corona electrode was set up to $-15 \mathrm{kV}$ and the roll electrode to $+15 \mathrm{kV}$. Assays were conducted with $5 \mathrm{~g}$ of powder. The products recovered in bin A (powder not attracted by the roll electrode) and B (powder attracted by the roll electrode) were weighted and the mass fraction in each bin was determined as the ratio of mass in the bin to the total mass (Figure 3). The losses correspond to particles that are first attracted by the roll electrode and then pushed after contact with it, so that they fell outside of the collecting bins. In both configurations, the mass of the powder attracted by the roll electrode was always low (less than $10 \%$ ). However, the losses, which may constitute until $95 \%$ of the total mass for ARH cl 2 correspond to particle reacting to the electrical field created by the roll electrode

Table 2: Configurations used in the separation tests

\begin{tabular}{|l|c|c|}
\hline $\begin{array}{l}\text { Voltage of the corona } \\
\text { electrode }\left(\mathrm{V}_{\mathrm{c}}\right)\end{array}$ & $0 \mathrm{kV}$ & $-15 \mathrm{kV}$ \\
\hline $\begin{array}{l}\text { Position of the corona } \\
\text { electrode }\left(\mathrm{d}_{\mathrm{c}}\right)\end{array}$ & $/$ & $90 \mathrm{~mm}$ \\
\hline $\begin{array}{l}\text { Voltage of the roll electrode } \\
\left(\mathrm{V}_{\mathrm{r}}\right)\end{array}$ & $+15 \mathrm{kV}$ \\
\hline $\begin{array}{l}\text { Distance roll electrode/ } \\
\text { conveyor }\left(\mathrm{d}_{\mathrm{e}}\right)\end{array}$ & $25 \mathrm{~mm}$ \\
\hline
\end{tabular}

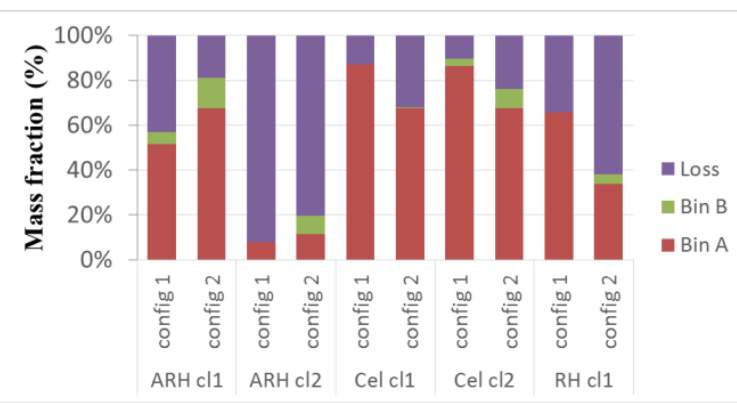

Fig. 3: Mass fractions recovered in each bin for configurations 1 and 2 .

In figure 3, the mass fractions recovered in bin $\mathrm{A}$ are more important for Cel cl 1, although its charge and size are similar to those of ARH cl 1. This can be explained by the elongated shape of cellulose particles. Indeed, the electric image force that pins the particles to the surface of the earthed conveyor belt is stronger on the flat ones (i.e cellulose particles).

The different assays highlights the fact that the electrical field generated by the roll electrode has a significant effect on the different powders and it is slightly enhanced by the corona discharge. However it is important to optimize the different parameters of the process to increase its efficiency. This has been achieved by means of experimental design methodology, using a model mixture of ARH1 and Cel Cl1, as described in the following section.

\subsection{Separation of a model mixture and of milled rice husk}

A Blend composed of $2.5 \mathrm{~g}$ of ARH cll and $2.5 \mathrm{~g}$ of Cel cll was separated on the device. These powders were chosen because their size characteristics are closer to 
those of ground rice husk. An additional bin (C) was placed on the side of the conveyor to recover a significant part of the losses due to the rebound of the particles after impact with the roll electrode. The mass of each material in each collecting bins (A, B and C) was determined by combustion of the vegetal part in a furnace at $900^{\circ} \mathrm{C}$ during 2 hours. The efficiency of the separation was determined based on two separations indexes (equation 3), one for the cellulose and one for the ash from rice husk, to integrate both the yield of the separation and the purity of the fractions. These indexes vary from 0 to $100 \%$, where 0 corresponds to the case where no separation is achieved (i.e. the composition of each fraction is equal to the composition of the initial blend) and $100 \%$ corresponding to the best separation (i.e. the case where each fraction is totally pure).

$$
I_{i}=\Sigma^{j}\left(m_{i j} *\left(c_{i j}-c_{i}\right)\right) /\left(m_{j}^{*}\left(1-c_{i}\right)\right)
$$

where $m_{i j}$ and $m_{j}$ are the mass of product $i$ recovered in the bin $i$ and the mass of the powder in the bin $j$, respectively; $c_{i j}$ and $c_{i}$ are the content of product $i$ in the bin $j$ and the initial content of the product $i$ in the blend. Based on preliminary works, in different assays the corona discharge was not activated. The velocity of the roll electrode $\left(v_{r}\right)$, and of the ground conveyor $\left(v_{c}\right)$, as well as the voltage of the roll electrode $\left(V_{r}\right)$ were varied. The distance roll electrode/conveyor was kept to $25 \mathrm{~mm}$ (minimum distance possible on the device) to maximize the electrical field effects. The separation indexes $I_{A R H}$ and $I_{C e l}$ were calculated and reported in table 3.

Table 3: Separation indexes for Ash from rice husk $\left(I_{A R H}\right)$ and Cellulose $\left(I_{c e l}\right)$ obtained in the different conditions.

\begin{tabular}{|c|c|c|c|c|c|}
\hline Case & $\begin{array}{c}V_{r} \\
(\mathrm{kV})\end{array}$ & $\begin{array}{c}v_{c} \\
(\mathrm{~m} / \mathrm{min})\end{array}$ & $\begin{array}{c}v_{r} \\
(\mathrm{rpm})\end{array}$ & $\begin{array}{c}I_{A R H} \\
(\%)\end{array}$ & $\begin{array}{c}I_{C e l} \\
(\%)\end{array}$ \\
\hline 1.0 & -15 & 2.6 & 12 & 7 & 10 \\
\hline 2.0 & -20 & 2.6 & 12 & 8 & 10 \\
\hline 3.0 & -25 & 2.6 & 12 & 11 & 10 \\
\hline 2.1 & -20 & 1.3 & 24 & 22 & 18 \\
\hline 3.1 & -25 & 1.3 & 24 & 27 & 24 \\
\hline 2.2 & -20 & 5.2 & 6 & 6 & 5 \\
\hline
\end{tabular}

An increase of the voltage and the velocity of the roll electrode together with a decrease of the conveyor velocity increase the efficiency of the separation. The best separation was achieved in case 3.1 for the highest voltage and velocity of the roll electrode and the slowest velocity of the conveyor. In this configuration, the centrifugal force is at is maximum and probably helps the particle to detach from the belt. In addition in case of a high roll electrode speed, attracted particles are less time in contact to the surface of the roll and stay pinned to it until removed by the scrapper. In case $3.1, m_{A}=0.15$ $\mathrm{g}$ with a $c_{A R H A}=53 \%, m_{B}=3.2 \mathrm{~g}$ with a $c_{A R H B}=37 \%$ in the bin B and $m_{C}=0.62 \mathrm{~g}$ with $c_{A R H_{-} C}=85.4 \%$.

The conditions 2.1 and 3.1 were applied to the separation of ground rice husk, a composite of organic and mineral parts, and the corresponding separation indexes $\left(I_{m}\right.$ and
$I_{v}$ ) are reported in table 4 . The indexes obtained were very low and the best conditions for ground rice husk differed from those of ARS/Cel blend. Indeed, the mineral and vegetal powders chosen in these works are not completely representative of the ground rice husk. In addition, the efficiency of the dissociation of the mineral and vegetal part during the milling step has not been assessed in this study.

Table 4: Separation indexes obtained for ground rice husk

\begin{tabular}{|c|c|c|c|c|c|}
\hline Case & $\begin{array}{c}\mathrm{V}_{\mathrm{r}} \\
(\mathrm{kV})\end{array}$ & $\begin{array}{c}\mathrm{V}_{\mathrm{c}} \\
(\mathrm{m} / \mathrm{min})\end{array}$ & $\begin{array}{c}\mathrm{V}_{\mathrm{r}} \\
(\mathrm{rpm})\end{array}$ & $\begin{array}{c}\mathrm{I}_{\mathrm{ARH}} \\
(\%)\end{array}$ & $\begin{array}{c}\mathrm{I}_{\mathrm{Cel}} \\
(\%)\end{array}$ \\
\hline 2.1 & -20 & 1.3 & 24 & 1 & 7 \\
\hline 3.1 & -25 & 1.3 & 24 & 0,3 & 2 \\
\hline
\end{tabular}

\section{Conclusion}

The aim of this work was to evaluate the potential of a corona-electrostatic separator to separate mineral and vegetal fractions of plant material. The behaviour of pure mineral and vegetal powders was studied on a customdesigned separator and has shown that mineral particles are strongly affected by induction effects due to the roll electrode. Based on an experimental design, a blend of vegetal and mineral powders $(50 / 50)$ was separated on the device with a significant enrichment in mineral in one fraction and vegetal in the other fraction. The conditions were applied to ground rice husk powder but the results obtained were not fully satisfactory. A new experimental bench, specifically adapted to ground rice husk powder will be set up in the future.

\section{References}

1. G. Ghizzi, D. Silva, S. Guilbert, X. Rouau, Powder Technol, 208, 2 pp. 266-270, (2011).

2. A. Barakat, C. Mayer-laigle, A. Solhy, R. A. D. Arancon, H. de Vries, R., Rsc Advances, 4(89): p. 48109-48127 (2014).

3. Y. Hemery, U. Holopainen, A-M. Lampi, P. Lehtinen, T. Nurmi, V. Piironen, M. Edelmann, X. Rouau, J Cereal Sci 53(1): p. 9-18, (2011)

4. J. Wang, M. de Wit, R. M. Boom, M.A.I. Schutyser, Separation and Purification Technology, 152(25): p. 164-171 (2015),

5. A. Barakat, and X. Rouau, Method for the fractionation of an oilseed cake, and applications of said method, Patent WO2015097290 A1. (2015).

6. T. Pandya, R. Srinivasan, and C. Thompson, Cereal Chem, 90(6): p. 535-539. (2013).

7. R. Delrue, and D.W.C.G. Van, Reduction of fibre content in fibre-containing oilseeds. Patent EP 1908355 A1 (2008)

8. A. Tilmatine, S. Flazi, K. Medles, Y. Ramdani, L. Dascalescu, J Electrostat, 61, p 21-30 (2004). 